\title{
INTERNALISASI NILAI KEBAIKAN MELALUI FUNGSI KEAGAMAAN DAN PENGONDISIAN LINGKUNGAN DAN DAMPAKNYA TERHADAP KARAKTER ANAK
}

\author{
Sri Dermawan ${ }^{1 *}$, Euis Sunartiं , Tin Herawati ${ }^{2}$ \\ 1 Program Studi IImu Keluarga dan Perkembangan Anak, Sekolah Pascasarjana, Institut Pertanian Bogor, Bogor \\ 16680, Indonesia \\ ${ }^{2}$ Departemen IImu Keluarga dan Konsumen, Fakultas Ekologi Manusia, Institut Pertanian Bogor, Bogor 16680, \\ Indonesia
}

*) E-mail: sriderma1@gmail.com

\begin{abstract}
Abstrak
Fenomena ibu bekerja mengindikasikan adanya perbedaan pelaksanaan fungsi keluarga yang berimplikasi terhadap karakter anak. Penelitian ini bertujuan menganalisis perbedaan dan pengaruh internalisasi nilai kebaikan melalui fungsi keagamaan dan pengondisian lingkungan terhadap karakter anak dari ibu bekerja dan ibu tidak bekerja. Penelitian ini menggunakan desai cross-sectional study, dengan lokasi penelitian di Desa Babakan, Kecamatan Dramaga, Kabupaten Bogor. Contoh penelitian berjumlah 121 pasang ibu dan anak (usia 9-11 tahun) yang dipilih dengan teknik stratified random sampling. Hasil penelitian menunjukkan bahwa ibu bekerja memiliki capaian yang lebih tinggi dibandingkan ibu tidak bekerja, yaitu pada variabel internalisasi nilai kebaikan melalui fungsi keagamaan khususnya dimensi keimanan dan karakter anak. Hal ini dikarenakan tingkat pendidikan ibu bekerja lebih tinggi dibandingkan ibu tidak bekerja sehingga ibu bekerja memiliki kemampuan menginternalisasikan nilai kebaikan jauh lebih baik, yang akhirnya memengaruhi peningkatan karakter anak. Hasil uji pengaruh menemukan bahwa karakteristik keluarga, internalisasi nilai kebaikan melalui fungsi keagamaan, dan pengondisian lingkungan berpengaruh langsung positif terhadap karakter anak. Penelitian ini merekomendasikan pentingnya peran pemerintah, perguruan tinggi, LSM, dan masyarakat luas dalam mendukung peningkatan ketahanan keluarga sehingga keluarga mampu melaksanakan tugas dan fungsinya secara optimal, khususnya dalam menginternalisasikan nilai kebaikan untuk peningkatan karakter anak melalui fungsi keagamaan dan pengondisian lingkungan.
\end{abstract}

Kata kunci: fungsi keagamaan, internalisasi nilai kebaikan, karakter anak, pengkondisan lingkungan

\section{Internalization of Virtue Values through Religious Functions and Environmental Conditioning and It's Effect on Child's Character}

\begin{abstract}
Phenomenon of working mothers indicated differences the implementation of family functions that could be have different influence on the child's character. This study aimed to analyze the differences and influence of internalization of virtue values through religious function and environmental conditioning on the child's character of working mothers and nonworking mothers. This research used cross-sectional design and conducted in Babakan Village, Dramaga Sub District, Bogor District. The participants of this study were 121 mothers and their children (9-11 years old) selected by stratified random sampling technique. The results showed that working mothers had higher internalization of virtue values through religious functions (faith dimension) and also their child had higher character than nonworking mothers. Working mothers have higher education so they have more ability to internalize the virtue values to their children. The result also found that family characteristic, internalization of virtue values through religious function, and environmental conditioning had a direct positive effect on child's character. This research recommends that government, universities, NGOs, and society to give support the family resilience so the family is able to perform their duties and functions optimally, especially in internalizing of virtue value to enhancement child's character through religious function and environmental conditioning.
\end{abstract}

Keyword: child's character, environmental conditioning, internalization of virtue values, religious function

\section{PENDAHULUAN}

Kemajuan suatu bangsa bergantung pada generasi muda. Karakter yang baik tidak terbentuk dalam jangka waktu yang pendek, tetapi butuh waktu bertahun-tahun. Oleh karena itu, sangat perlu dilakukan penanaman karakter yang baik kepada anak sejak dini, sehingga nanti ketika telah dewasa dan memikul tanggung jawab untuk meneruskan 
pembangunan bangsa, mereka telah siap. Teori ekologi menyebutkan bahwa keluarga merupakan lingkungan sosial terkecil yang pertama dan utama dalam memengaruhi perkembangan karakter anak. Pembentukan karakter yang baik pada anak adalah salah satu tugas dan fungsi keluarga, yang diantaranya dapat dilakukan dengan internalisasi nilai kebaikan melalui fungsi keagamaan dan pengondisian lingkungan.

Internalisasi nilai kebaikan yakni proses penanaman kebaikan ke dalam diri anak melalui pembinaan, bimbingan dan pemberian contoh, agar anak menguasai secara mendalam nilai kebaikan tersebut serta menghayati dan mengamalkannya sehingga dapat tercermin dalam sikap dan tingkah laku yang baik. Internalisasi nilai kebaikan melalui fungsi keagamaan, yang selanjutnya disebut sebagai internalisasi fungsi keagamaan adalah proses penanaman nilai kebaikan melalui fungsi keagamaan keluarga. Fungsi keagamaan keluarga artinya keluarga merupakan tempat di mana seluruh anggotanya memelihara nilai agama dan menjalankan aktivitas keagamaan (BKKBN, 1996). Banyak penelitian tentang pentingnya fungsi keagamaan keluarga yang di antaranya menyatakan bahwa keyakinan beragama (iman) memegang peranan penting bagi ibu dalam menjalani perannya untuk mengasuh anak (Madden, Aguiniga, \& Zellman, 2014). Selain itu, seorang ibu wajib menanamkan nilai-nilai keagamaan yang baik ke dalam dirinya sendiri sebelum menanamkan nilai-nilai keagamaan kepada anak-anaknya kelak. Keluarga yang memiliki kekuatan dalam penerapan nilai agama akan memiliki hubungan sosial yang sehat sehingga akan kuat dalam menghadapi masalah dalam keluarga (Sunarti \& Fitriani, 2010).

Ketidakberfungsian pada keluarga dapat terjadi karena masalah pemenuhan ekonomi (Raharjo, Puspitawati, \& Krisnatuti, 2015). Peningkatan level pendidikan wanita dan semakin luasnya kesempatan kerja membuat semakin banyak wanita yang memasuki lapangan pekerjaan (Hakim, Sunarti, \& Herawati, 2014). Fenomena ibu bekerja mengindikasikan adanya perbedaan penanaman nilai kebaikan melalui fungsi keluarga yang diterapkan kepada anak antara ibu bekerja dengan ibu yang tidak bekerja (Sunarti, 2005). Motif ekonomi yaitu untuk pemenuhan kebutuhan keluarga menjadi alasan utama ibu untuk bekerja sehingga harus membagi waktu antara peran domestik dengan peran publik (Sunarti et al., 2013).
Kondisi ibu yang bekerja dalam sektor publik mengakibatkan intensitas waktu yang diberikan oleh ibu kepada anak akan semakin sedikit (Rizkillah, Sunarti, \& Herawati, 2015; Eliana \& Ratina, 2007). Fokus dan profesionalitas ibu dalam pekerjaan membuat waktu untuk keluarga berkurang (Sunarti, 2013). Padahal banyak hasil studi yang menemukan bahwa karakter anak akan semakin baik dengan semakin besarnya alokasi waktu yang diberikan keluarga (Elmanora, Muflikhati, \& Alfiasari, 2012; Rahmiati \& Puspitawati, 2013).

Seorang ibu harus mampu menyusun suatu strategi yang dapat menjembatani peran di tempat kerja dan peran dalam rumah tangga sehingga dapat lebih optimal dalam pelaksanaan fungsinya. Hal ini harus dilakukan agar tidak memicu terjadinya penyimpangan karakter anak karena berada pada kondisi kurangnya pengawasan dari orangtua (Meliani, Sunarti, \& Krisnatuti, 2014). Cara yang efektif untuk mengubah dan mengontrol karakter ini adalah dengan melakukan penguatan (reinforcement) berupa pengondisian lingkungan. Pengaruh lingkungan sosial dapat menyebabkan masalah pada karakter anak. Salah satu pengaruh negatif yang ada saat ini banyak diberikan oleh media informasi. Hasil penelitian menunjukkan bahwa semakin sering anak mengakses media sosial berhubungan dengan rendahnya karakter yang dimilikinya (Rahmawati, Hastuti, \& Herawati, 2014). Kondisi lingkungan yang baik, termasuk kondisi keagamaan dapat membantu keluarga dalam menerapkan nilai-nilai yang baik.

Dalam konteks kehidupan sosial, internalisasi nilai dimulai dari keluarga, lingkungan atau kelompok masyarakat yang lebih luas (Sunarti, 2015). Apabila pembagian peran dan waktu tidak dikelola dengan baik, maka akan berakibat tidak tercapainya pemenuhan peran dan fungsi ibu dalam keluarga sehingga dapat menurunkan kualitas kehidupan keluarga dan lebih mengarahkan orangtua kepada praktik pengondisian lingkungan anak yang negative yang akhirnya akan merugikan anak (Alam, Sattar \& Chaudhury, 2011). Peran ganda yang dimiliki oleh wanita atau ibu bekerja menyebabkannya mendapat tuntutan baik dari sektor domestik dan sektor publik. Hal tersebut dapat menyebabkan terjadinya kesulitan pada ibu terlebih ketika ibu memiliki jam kerja yang panjang, perjalanan yang cukup lama, dan pengalaman bekerja yang sedikit (Almasitoh, 2011). Parveen (2009) menyatakan bahwa apabila pekerja adalah seorang ibu maka kesulitan dalam pembagian peran dan waktu 
dapat terjadi. Hasil studi Herawati (2012) terhadap keluarga di Kabupaten Bogor menemukan bahwa tidak sepenuhnya orangtua menerapkan fungsi keagamaan terhadap anak karena orangtuanya sendiri jarang mengamalkan keagamaan. Tidak heran jika saat ini kondisi karakter anak usia sekolah dasar di Kabupaten Bogor cukup memprihatinkan. Puspitasari, Hastuti, dan Herawati (2016) menyatakan bahwa berdasarkan data Kapolsek Kabupaten Bogor, ada kasus tindak pidana yang dilakukan oleh anak usia sekolah dasar setiap tahun di antaranya pencabulan, persetubuhan, dan perkosaan.

Kondisi lain tentang masalah lemahnya fungsi keagamaan keluarga terdeteksi melalui peningkatan pekerja wanita yang menyebabkan peningkatan peran orangtua tunggal bahkan perceraian. Dalam buku orasi ilmiah (Sunarti, 2015) disebutkan bahwa menurut Badan Urusan Peradilan Agama Mahkamah Agung, dari 2 juta perkawinan pada tahun 2010 terjadi 285184 perceraian (782 perceraian per hari) di mana 70,0 persen diajukan oleh perempuan. Sementara itu catatan Komnas Perempuan terjadi peningkatan kasus kekerasan (psikis, ekonomi, fisik) terhadap perempuan dari 119 107 pada tahun 2011 menjadi 293200 pada tahun 2014, serta informasi yang terkumpul dari kegiatan seleksi motivator ketahanan keluarga (Motekar) di 200 desa dari 27 kabupaten dan kota di Provinsi Jawa Barat mengungkap besarnya masalah moral (perselingkuhan dan kekerasan) yang terjadi dalam lingkungan keluarga dan masyarakat.

Oleh karena itu, orangtua harus melakukan peningkatan fungsi keagamaan keluarga agar kesadaran moral keluarga pun meningkat, sehingga penanaman karakter yang baik pada anak dapat terjadi secara optimal. Tujuan penelitian ini adalah untuk menganalisis perbedaan karakteristik keluarga, karakteristik anak, internalisasi nilai kebaikan melalui fungsi keagamaan, pengondisian lingkungan, dan karakter anak pada ibu bekerja dan ibu tidak bekerja. Selain itu, penelitian ini juga bertujuan menganlisis pengaruh karakteristik keluarga, karakteristik anak, internalisasi nilai kebaikan melalui fungsi keagamaan dan pengondisian lingkungan terhadap karakter anak pada ibu bekerja dan ibu tidak bekerja.

\section{METODE}

Desain penelitian ini adalah cross-sectional study, yaitu pengambilan data penelitian dilakukan dalam satu kali waktu secara bersamaan pada obyek yang berbeda. Penelitian ini dilakukan di Desa Babakan, Kecamatan Dramaga, Kabupaten Bogor dengan alasan bahwa daerah tersebut termasuk salah satu daerah dengan jumlah penduduk usia 9-11 tahun terbanyak (BPS 2015). Rentang waktu penelitian yang terdiri dari kegiatan persiapan, pengumpulan data, pengolahan data, analisis data, dan penulisan laporan terhitung mulai bulan Desember 2016 hingga Juli 2017.

Populasi dalam penelitian ini adalah keluarga yang memiliki anak dengan usia antara 9 sampai dengan 11 tahun yang sebagian ibunya bekerja dan sebagiannya lagi tidak bekerja. Teknik penarikan contoh pada penelitian ini dilakukan dengan menggunakan teknik statified random sampling. Jumlah contoh yang diambil untuk penelitian ini adalah 121 pasang ibu dan anak yang ditentukan berdasarkan rumus yang diacu dari Slovin (1960). Sebanyak 60 pasang anak dan ibu diambil dari keluarga dengan ibu bekerja, sedangkan 61 pasang lainnya berasal dari keluarga dengan ibu tidak bekerja.

Data yang dikumpulkan merupakan data primer dan sekunder. Data sekunder berupa gambaran umum penelitian menurut lokasi penelitian yang diambil dari pemerintah Desa Babakan, Kecamatan Dramaga, Kabupaten Bogor. Data primer diperoleh dari hasil penggalian informasi dari responden ibu dan anak, dengan teknik wawancara menggunakan kuesioner yang meliputi karakteristik keluarga (usia ayah dan ibu, lama pendidikan ayah dan ibu, jenis pekerjaan ayah dan ibu, pendapatan per kapita dan besar keluarga), karakteristik anak (usia dan jenis kelamin anak), internalisasi nilai kebaikan melalui fungsi keagamaan, pengondisian lingkungan, dan karakter anak.

Karakteristik keluarga responden terdiri dari usia ayah dan ibu, lama pendidikan ayah dan ibu, pekerjaan ibu, pendapatan per kapita dan besar keluarga. Usia ayah dan ibu diukur berdasarkan tahun, lalu dikelompokkan berdasarkan kategorisasi yang dikemukakan oleh Santrock (2012) yaitu dewasa awal (20$40)$, dewasa menengah (>40-60), dewasa akhir (>60). Data pendidikan orangtua dikelompokkan berdasarkan lamanya pendidikan yang ditempuh oleh orangtua. Pekerjaan orangtua dikelompokkan menjadi kelompok tidak bekerja dan bekerja. Penentuan pendapatan perkapita keluarga ditentukan berdasarkan acuan dari BPS 
Kabupaten Bogor (2015) yang mengelompokkan pendapatan keluarga menjadi dua kategori, yaitu kategori miskin (penghasilan $\leq R p 271.970,00$ ) dan kategori tidak miskin (penghasilan >Rp271.970,00). Besar keluarga dikelompokkan menjadi empat kategori, yatu keluarga kecil (jumlah anggota keluarga $\leq 4$ ), keluarga sedang (jumlah anggota keluarga 5-7), dan keluarga besar (jumlah anggota keluarga $>7$ ). Karakteristik anak meliputi usia dan jenis kelamin anak.

Kuesioner internalisasi nilai kebaikan melalui fungsi keagamaan keluarga berjumlah 22 pertanyaan yang kemudian dimodifikasi menjadi 30 pertanyaan menggunakan instrumen Multidimensional Measure of Religiousity (Glocks \& Stark, 1968), dengan skala Likert 1-4 (1=tidak pernah; 2=kadangkadang; $3=$ sering; $4=$ selalu) dan nilai Cronbach's alpha adalah 0,835. Kuesioner pengondisian lingkungan berjumlah 28 pertanyaan yang kemudian dimodifikasi menjadi 30 pertanyaan menggunakan instrumen Family Environment Scale (Felton, Brooks, \& Robert, 1994), dengan skala Guttman (1=tidak; 2=ya) dan nilai Cronbach's alpha adalah 0,857 . Kuesioner karakter anak dimodifikasi dari instrumen Values in Action Youth oleh Peterson dan Seligman (2004) yang berjumlah 24 pertanyaan menjadi 35 pertanyaan, dengan skala Likert 1-4 (1=tidak pernah; 2=kadang-kadang; $3=$ sering; $4=$ selalu) dan nilai Cronbach's alpha adalah 0,871.

Pengolahan data dilakukan dengan melalui beberapa tahap kegiatan yaitu editing (penyuntingan data), coding (pengkodean data), entering (memasukkan data), cleaning (pembersihan data), scoring (pemberian skor) dan analysis (analisis data yang meliputi analisis deskriptif dan inferensia.

Pengkategorian untuk internalisasi nilai kebaikan melalui fungsi keagamaan, pengondisian lingkungan, dan karakter anak dilakukan berdasarkan nilai skor kemudian ditransformasikan ke dalam bentuk indeks. Skor indeks yang dicapai dikategorikan berdasarkan rentang kelas. Cut-off point (Yimer, Abera, \& Mulu, 2013) yang digunakan dalam pengkategorian yakni; rendah $(0,00$ $60,00)$, sedang $(60,00-80,00)$, dan tinggi $(80,00-100,00)$.

Analisis inferensia yang digunakan dalam menjawab tujuan penelitian adalah analisis uji beda T-test dan uji pengaruh menggunakan Smart Partial Least Square. Uji beda T-test digunakan untuk melihat apakah terdapat perbedaan antara karakteristik keluarga, karakteristik anak, penanaman nilai-nilai kebaikan melalui fungsi keagamaan, pengondisian lingkungan, dan karakter anak usia sekolah dengan ibu bekerja dan ibu tidak bekerja. Sementara, Smart Partial Least Square digunakan untuk menganalisis pengaruh karakteristik keluarga, karakteristik anak, internalisasi nilai kebaikan melalui fungsi keagamaan, dan pengondisian lingkungan terhadap karakter anak.

\section{HASIL}

\section{Karakteristik Keluarga dan Anak}

Hasil penelitian total karakteristik keluarga menunjukkan lebih dari separuh usia ayah $(59,5 \%)$ berada pada kelompok usia dewasa menengah, sedangkan usia ibu berada pada usia dewasa awal (62,8\%). Secara umum, rata-rata usia ayah adalah 41,80 tahun dan rata-rata usia ibu 37,72 tahun. Rentang usia ayah pada penelitian ini antara 32 sampai dengan 63 tahun dan usia ibu antara usia 28 sampai dengan 53 tahun. Kurang dari separuh lama pendidikan ayah $(48,8 \%)$ dan ibu $(47,1 \%)$ memiliki lama pendidikan yang setara dengan tamatan Sekolah Menengah Atas (SMA). Ratarata lama pendidikan ayah adalah 12,05 tahun dan lama pendidikan ibu adalah 11,37 tahun. Rentang lama pendidikan ayah pada penelitian ini antara 6 sampai dengan 19 tahun dan lama pendidikan ibu pada rentang 6 sampai dengan 18 tahun. Lebih dari separuh keluarga $(60,3 \%)$ berada pada kelompok keluarga kecil, dengan rata-rata jumlah anggota keluarga sebanyak 4 orang. Rentang besar keluarga pada penelitian ini antara 3 sampai dengan 10 orang.

Lebih dari separuh ayah anak dengan ibunya bekerja berada pada kelompok usia dewasa menengah $(63,3 \%)$ dengan rata-rata usia ayah 42,15 tahun. Lebih dari seperdua usia ibu bekerja berada pada kelompok usia dewasa awal $(56,7 \%)$ dengan rata-rata usia ibu 38,53 tahun. Sebagian besar lama pendidikan ayah anak yang ibunya bekerja memiliki tingkat pendidikan Sekolah Menengah Atas (SMA) dengan rata-rata lama pendidikan 12,30 tahun. Sekitar 38,3 persen lama pendidikan ibu bekerja memiliki tingkat pendidikan yang setara dengan Sekolah Menengah Atas (SMA). Rata-rata lama pendidikan ibu bekerja adalah 12,45 tahun.

Lebih dari separuh lama pendidikan ayah anak yang ibunya tidak bekerja memiliki tingkat pendidikan yang setara dengan Sekolah Menengah Atas (SMA) dengan rata-rata lama 
pendidikan ayah adalah 11,80 tahun. Sekitar 5,7 persen ibu tidak bekerja memiliki tingkat pendidikan setara dengan Sekolah Menengah Atas (SMA). Rata-rata lama pendidikan ibu tidak bekerja adalah 10,31 tahun. Hasil uji beda menunjukkan bahwa terdapat perbedaan yang signifikan $(p=0,001)$ antara pendidikan ibu bekerja dan ibu tidak bekerja.

Kurang dari separuh ibu bekerja (35,0\%) memilih menjadi wiraswasta dan guru $(26,7 \%)$. Selebihnya pekerjaan ibu yang lainnya sebagai Pegawai Negeri Sipil (PNS), buruh dan asisten rumah tangga. Hal ini memperlihatkan bahwa pencari nafkah utama keluarga dalam penelitian ini bukan hanya ayah saja tetapi juga ibu. Separuh ayah dari keluarga ibu bekerja $(56,7 \%)$ dan keluarga ibu tidak bekerja $(54,1 \%)$ memiliki pekerjaan sebagai wiraswasta. Pekerjaan selanjutnya yang dimiliki oleh ayah dari keluarga ibu bekerja $(13,3 \%)$ dan keluarga ibu tidak bekerja $(24,6 \%)$ adalah buruh. Pekerjaan ayah yang lainnya sebagai PNS, guru, buruh, asisten rumah tangga dan tidak bekerja.

Lebih dari separuh besar keluarga ibu bekerja $(65,5 \%)$ dan ibu tidak bekerja $(55,7 \%)$ berada pada kelompok keluarga kecil, dengan ratarata jumlah anggota keluarga empat orang. Pendapatan perkapita yang dimiliki oleh keluarga ibu bekerja dan ibu tidak bekerja berada di kisaran Rp70.000,00 sampai dengan Rp2.375.000,00. Tidak terdapat perbedaan yang signifikan pada pendapatan keluarga ibu bekerja dan ibu tidak bekerja. Rata-rata pendapatan keluarga ibu bekerja berada pada kisaran Rp1.000.000,00 sampai dengan Rp2.375.000,00, sedangkan rata-rata pendapatan keluarga ibu tidak bekerja berada pada kisaran Rp70.000,00 sampai dengan kisaran Rp2.333.333,00. Berdasarkan nilai pengelompokkan pendapatan keluarga oleh BPS Kabupaten Bogor tahun 2015, lebih dari tiga perempat $(76,9 \%)$ dari seluruh keluarga tergolong tidak miskin.

Tabel 1 Hasil uji beda capaian fungsi keagamaan (indeks) berdasarkan status pekerjaan ibu

\begin{tabular}{|c|c|c|c|}
\hline \multirow{2}{*}{$\begin{array}{c}\text { Fungsi } \\
\text { keagamaan }\end{array}$} & \multicolumn{2}{|c|}{ Rata-rata } & \multirow[b]{2}{*}{$p$-value } \\
\hline & Bekerja & $\begin{array}{c}\text { Tidak } \\
\text { bekerja }\end{array}$ & \\
\hline Keimanan & 87,30 & 80,43 & $0,007^{*}$ \\
\hline Pengetahuan & 77,22 & 73,22 & 0,214 \\
\hline Pengalaman & 82,33 & 81,96 & 0,901 \\
\hline Ritual & 85,46 & 83,51 & 0,427 \\
\hline $\begin{array}{l}\text { Konsekuensi } \\
\text { sosial }\end{array}$ & 46,20 & 43,53 & 0,414 \\
\hline Total & 75,87 & 72,49 & 0,106 \\
\hline
\end{tabular}

Penelitian ini melibatkan 121 anak yang terdiri atas 31 anak laki-laki (25,6\%) dan 30 anak perempuan $(24,8 \%)$ dari contoh ibu tidak bekerja serta 30 anak laki-laki $(24,8 \%)$ dan 30 anak perempuan $(24,8 \%)$ dari contoh ibu bekerja. Rata-rata usia anak secara keseluruhan adalah 10,12 tahun. Hasil uji beda menunjukkan tidak terdapat perbedaan signifikan antara usia anak pada ibu bekerja dan tidak bekerja.

\section{Internalisasi Nilai Fungsi Keagamaan}

Tabel 1 menunjukkan capaian keseluruhan internalisasi nilai kebaikan melalui fungsi keagamaan keluarga terkategori sedang untuk ibu bekerja $(75,87)$ dan ibu tidak bekerja $(72,49)$. Hal ini menunjukkan pelaksanaan fungsi keagamaan keluarga yang dilakukan oleh ibu bekerja maupun ibu tidak bekerja sudah sudah cukup baik. Ibu bekerja memiliki capaian tertinggi pada semua dimensi fungsi keagamaan keluarga, baik pada dimensi keimanan $(87,30)$, pengetahuan $(77,22)$, pengalaman $(82,33)$, ritual $(85,46)$, dan konsekuensi sosial $(46,20)$. Hasil uji beda internalisasi fungsi keagamaan menunjukkan bahwa terdapat perbedaan yang signifikan pada dimensi keimanan dengan ibu bekerja memiliki capaian yang lebih tinggi $(87,30)$ dibandingkan ibu yang tidak bekerja $(80,43)$. Hal ini disebabkan tingkat pendidikan ibu bekerja yang lebih tinggi dibanding tingkat pendidikan ibu tidak bekerja.

\section{Pengondisian Lingkungan}

Tabel 2 menunjukkan bahwa ibu yang bekerja memiliki capaian lebih tinggi pada dimensi lingkungan sosial $(72,02)$ dibandingkan ibu yang tidak bekerja $(71,84)$. Sebaliknya pada dimensi media informasi, ibu yang tidak bekerja memiliki capaian lebih tinggi $(89,92)$ dibandingkan ibu yang bekerja $(87,61)$. Tidak ada perbedaan yang signifikan pada variabel pengondisian lingkungan $(p=0,823)$ antara ibu bekerja dengan ibu tidak bekerja. Hal ini berarti meskipun ibu bekerja, namun tetap memiliki kemampuan untuk mengontrol dan mengondisikan lingkungan anak mereka.

Tabel 2 Hasil uji beda capaian pengondisian lingkungan (indeks) berdasarkan status pekerjaan ibu

\begin{tabular}{lccc}
\hline \multirow{2}{*}{$\begin{array}{c}\text { Pengondisian } \\
\text { lingkungan }\end{array}$} & \multicolumn{3}{c}{ Rata-rata } \\
Bekerja & $\begin{array}{c}\text { Tidak } \\
\text { bekerja }\end{array}$ & p-value \\
\hline Sosial & 72,02 & 71,84 & 0,925 \\
Media informasi & 87,61 & 89,92 & 0,406 \\
Total & 75,66 & 76,06 & 0,823 \\
\hline Keterangan: ${ }^{* *}$ ) signifikansi 0,$01 ;{ }^{*}$ ) & signifikansi 0,05
\end{tabular}


Tabel 3 Hasil uji beda capaian karakter anak (indeks) berdasarkan status pekerjaan ibu

\begin{tabular}{|c|c|c|c|}
\hline \multirow[b]{2}{*}{ Karakter anak } & \multicolumn{2}{|c|}{ Rata-rata } & \multirow[b]{2}{*}{$p$-value } \\
\hline & Bekerja & $\begin{array}{l}\text { Tidak } \\
\text { bekerja }\end{array}$ & \\
\hline Kejujuran & 84,68 & 55,58 & $0,000^{\star \star}$ \\
\hline Kepedulian & 76,80 & 67,00 & $0,001^{\star *}$ \\
\hline Bekerjasama & 51,11 & 49,31 & 0,496 \\
\hline $\begin{array}{l}\text { Kemauan } \\
\text { berbagi }\end{array}$ & 44,58 & 43,23 & 0,589 \\
\hline $\begin{array}{l}\text { Menyelesaikan } \\
\text { masalah }\end{array}$ & 70,13 & 71,24 & 0,729 \\
\hline Total & 72,39 & 63,87 & $0,000^{\star *}$ \\
\hline
\end{tabular}

\section{Karakter Anak}

Tabel 3 menunjukkan bahwa anak yang ibunya bekerja memiliki capaian lebih tinggi pada variabel karakter anak secara keseluruhan $(72,39)$. Selain itu, hampir semua dimensi variable karakter, anak yang ibunya bekerja juga memiliki capaian lebih baik dibandingkan dengan anak yang ibunya tidak bekerja, yaitu dimensi kejujuran $(84,68)$; kepedulian $(76,80)$; bekerjasama $(51,11)$, dan kemauan berbagi $(44,58)$. Sementara itu, pada dimensi menyelesaikan masalah, anak yang ibunya tidak bekerja $(71,24)$ memiliki capaian lebih baik dibandingkan dengan ibu yang bekerja $(70,13)$.

Hasil uji beda menemukan bahwa terdapat perbedaan yang signifikan antara anak yang ibunya bekerja dan tidak bekerja pada variabel karakter anak total $(p=0,000)$ dengan capaian ibu bekerja lebih baik dibanding ibu tidak bekerja. Perbedaan signifikan juga ditemukan pada capaian dimensi kejujuran $(p=0,000)$ dan kepedulian $(p=0,001)$. Selanjutnya, temuan penelitian menunjukkan baik anak dari kelompok ibu bekerja maupun tidak bekerja, keduanya memiliki capaian yang rendah pada dimensi bekerjasama dan kemauan untuk berbagi. Hal ini dapat dilihat dari skor capaian anak dari kelompok ibu bekerja dan ibu tidak bekerja masing-masing $(51,11$ dan 44,58$)$ serta $(49,31$ dan 43,23$)$.

\section{Faktor-Faktor yang Memengaruhi Karakter Anak}

Faktor- faktor yang saling berpengaruh dalam penelitian ini dianalisis menggunakan Partial Least Square (PLS) seperti yang ditunjukkan pada Tabel 4. Analisis PLS dapat dilakukan apabila telah memenuhi syarat-syarat inner dan outer model. Setelah melakukan pengujian inner dan outer model maka diketahui bahwa tidak semua indikator dalam penelitian ini valid dan reliabel untuk dilakukan analisis lanjutan, hanya indikator karakteristik keluarga (pendidikan ibu, usia ibu, status pekerjaan ibu dan pendapatan perkapita), indikator internalisasi nilai fungsi keagamaan, dan pengondisian lingkungan yang memenuhi syarat analisis PLS. Sementara itu, indikator karakteristik anak (usia dan jenis kelamin) tidak dapat dianalisis menggunakan model PLS karena tidak memenuhi syarat inner dan outer model.

Tabel 4 menunjukkan bahwa karakteristik keluarga (lama pendidikan ibu, usia ibu, status pekerjaan ibu dan pendapatan keluarga) $(\beta=0,298 ; t>1,96)$, internalisasi nilai kebaikan melalui fungsi keagamaan keluarga $(\beta=0,194$; $t>1,96)$ dan pengondisian lingkungan $(\beta=0,233 ; t>1,96)$ berpengaruh langsung positif signifikan terhadap karakter anak. Hal ini berarti semakin tinggi pendidikan ibu, usia ibu dan pendapatan perkapita keluarga, maka semakin baik karakter anaknya. Begitu pula dengan internalisasi nilai fungsi keagamaan dan pengondisian lingkungan yang semakin tinggi, maka karakter anaknya akan semakin baik.

Status bekerja ibu yang berpengaruh positif terhadap karakter anak bukan berarti semakin ibu bekerja maka karakter anak akan semakin baik, namun karena ibu yang bekerja memiliki tingkat pendidikan yang tinggi sehingga ibu bekerja lebih mampu dan mengetahui cara menanamkan nilai kebaikan ke dalam diri anak, hal inilah yang diduga menjadi faktor yang memengaruhi perkembangan karakter anak. Hasil uji pengaruh model karakteristik keluarga, penanaman nilai kebaikan melalui fungsi keagamaan dan pengondisian lingkungan terhadap karakter anak menunjukkan angka $R$-square adalah 0,187 (Gambar 1), yang menjelaskan bahwa 18,7 persen model variabel-variabel memengaruhi karakter anak dan sisanya sebesar 81,3 persen dipengaruhi oleh variabel lain.

Tabel 4 Hasil uji pengaruh antar variabel

\begin{tabular}{lccc}
\hline \multicolumn{1}{c}{ Variabel } & $\begin{array}{c}\text { Pengaruh } \\
\text { langsung }\end{array}$ & $\begin{array}{c}\text { Pengaruh } \\
\text { tidak } \\
\text { langsung }\end{array}$ & $\begin{array}{c}\text { Total } \\
\text { pengaruh }\end{array}$ \\
\hline Karakteristik & $0,298^{*}$ & 0,021 & $0,319^{*}$ \\
keluarga & $0,194^{*}$ & $-0,015$ & $0,179^{*}$ \\
$\begin{array}{l}\text { Fungsi } \\
\text { keagamaan }\end{array}$ & $0,233^{*}$ & - & $0,233^{*}$ \\
$\begin{array}{l}\text { Pengondisian } \\
\text { lingkungan }\end{array}$ & & & \\
\hline $\mathrm{R}^{2}$ & & \\
Adj, $\mathrm{R}^{2}$ & & 0,187 & \\
$\mathrm{n}$ & 0,166 & \\
\hline Keterangan: ${ }^{*}$ ) signifikansi t> 1,96 & 121 & \\
\end{tabular}




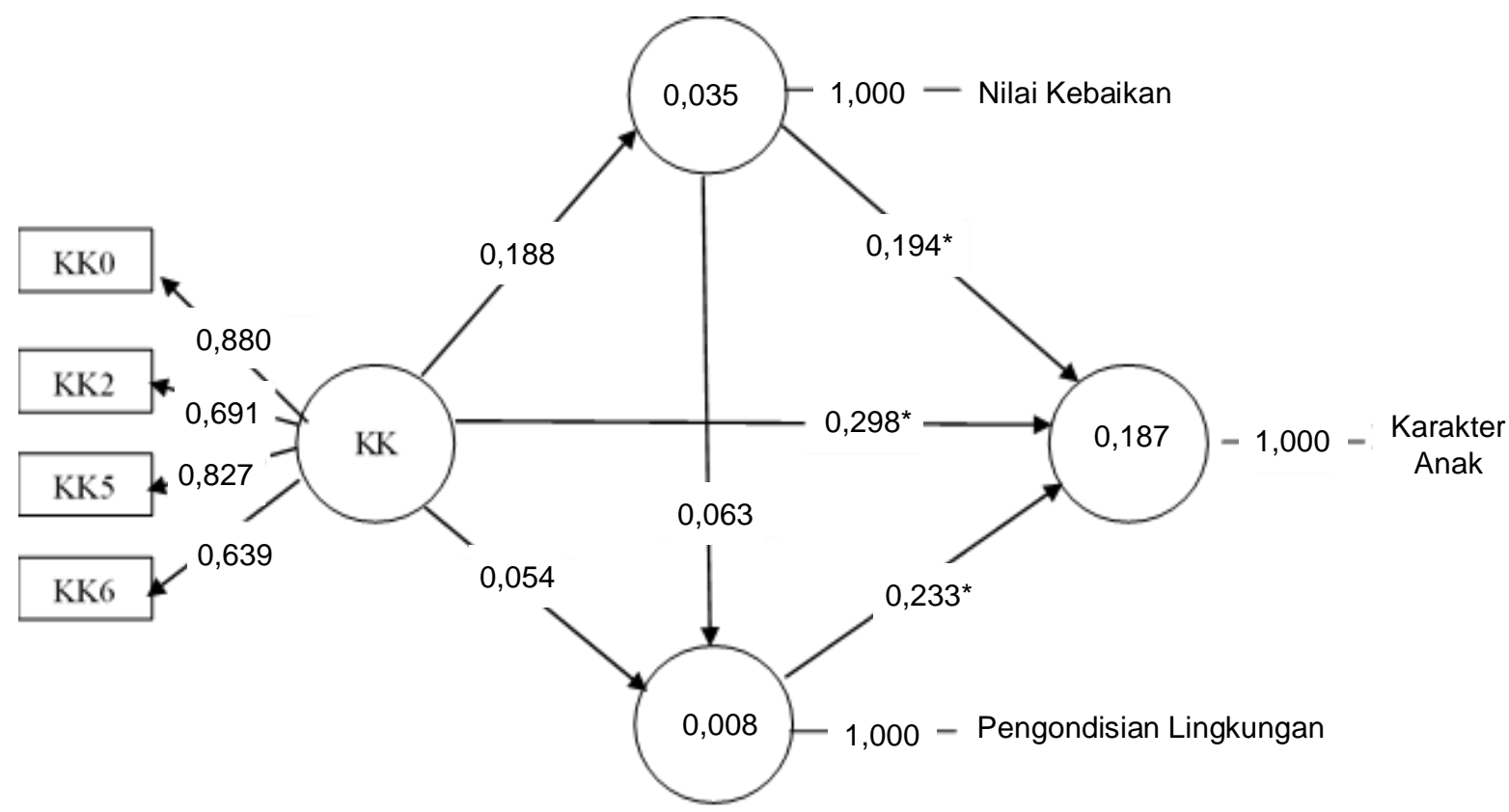

Keterangan:

KK: karakteristik keluarga

KKO; lama pendidikan ibu

KK2; usia ibu

KK5; status kerja ibu

KK6; pendapatan keluarga

NK; $\quad$ fungsi keagamaan
PL; $\quad$ pengondisian lingkungan
KTA; karakter anak
$\longrightarrow$; nilai outer loadings

Gambar 1 Model pengaruh karakteristik keluarga, internalisasi nilai fungsi keagamaan dan pengondisian lingkungan terhadap karakter anak

\section{PEMBAHASAN}

Hasil penelitian menunjukkan bahwa internalisasi nilai fungsi keagamaan terkategori sedang, yang berarti pelaksanaan fungsi keagamaan keluarga sudah cukup baik. Selanjutnya internalisasi nilai kebaikan melalui fungsi keagamaan pada dimensi keimanan berbeda nyata antara ibu bekerja dan ibu tidak bekerja, dengan rata-rata skor indeks keimanan pada ibu bekerja lebih tinggi dari pada ibu tidak bekerja. Hal ini memperlihatkan bahwa ibu bekerja lebih tinggi menanamkan nilai kebaikan melalui dimensi keimanan kepada anaknya dibandingkan dengan ibu tidak bekerja. Temuan ini sejalan dengan hasil penelitian yang dilakukan oleh Almani et al. (2012); Wardhani, Sunarti, dan Muflikhati (2017) bahwa ibu yang bekerja mampu membangun nilai yang baik dalam diri anak. Dechant dan Schulz (2014) menyatakan bahwa keluarga ibu bekerja dengan tingkat pendidikan yang tinggi, penghasilan, dan pekerjaan yang baik akan menunjukkan nilainilai karakter yang baik dalam kehidupan sosialnya serta menanamkan nilai pengasuhan yang seharusnya, meskipun tidak semua pasangan mampu menerapkan nilai-nilai ini dalam kehidupan nyata mereka.
Pengondisian lingkungan dalam penelitian tidak berbeda nyata antara ibu bekerja dan tidak bekerja, namun rata-rata skor indeks pengondisian lingkungan dimensi sosial pada keluarga ibu bekerja lebih tinggi dari pada ibu tidak bekerja. Hal ini memperlihatkan bahwa ibu bekerja lebih banyak mengontrol kondisi lingkungan sosial anaknya dibandingkan dengan ibu tidak bekerja. Sementara itu, pada dimensi lingkungan media informasi, rata-rata skor indeks pada keluarga ibu tidak bekerja lebih tinggi dibanding ibu bekerja. Hal ini berarti keluarga yang ibunya tidak bekerja lebih intens dalam mengontrol sumber-sumber informasi yang didapatkan oleh anaknya. Kelompok ibu tidak bekerja memiliki alokasi waktu pengasuhan anak dan pengelolaan rumah tangga yang seimbang sehingga memungkinkan ibu untuk melakukan pengasuhan dengan pengondisian lingkungan yang lebih intens dibanding ibu bekerja yang waktunya harus terbagi antara keluarga dan pekerjaan. Namun status pendidikan yang rendah mengakibatkan ibu tidak bekerja memiliki pengetahuan yang terbatas dalam mengorganisasikan lingkungan anak (Sunarti, 2014). Hal inilah yang kemudian menyebabkan karakter anak dari kelompok ibu tidak bekerja lebih rendah dibanding ibu bekerja. 
Orangtua memainkan peran secara harmonis dan holistik untuk anak (Runcan \& Goian, 2014). Hasil uji beda menemukan bahwa anak yang ibunya bekerja memiliki karakter yang lebih baik dibanding ibu tidak bekerja, terutama pada dimensi kejujuran dan kepedulian. Hal ini dikarenakan ibu bekerja memiliki tingkat pendidikan yang lebih tinggi dan pengetahuan dan keterampilan yang dimiliki lebih baik dibandingkan ibu tidak bekerja sehingga kemampuan dalam menginternalisasikan nilai kebaikan karakter kepada anaknya lebih baik dibandingkan ibu tidak bekerja (Rizkillah, Sunarti dan Herawati, 2015). Faktor inilah yang berdampak positif terhadap peningkatan karakter anak. Penelitian lain juga menunjukkan bahwa anak-anak yang keluarganya memiliki pekerjaan yang baik menunjukkan lebih banyak empati dan perilaku positif terhadap anak-anak lain (Spinrad \& Eisenberg, 2009; Romano, Kohen, \& Findlay, 2010).

Rendahnya capaian pada dimensi bekerjasama dan kemauan untuk berbagi yang ditunjukkan oleh anak-anak dalam penelitian ini mengindikasikan adanya masalah perkembangan karakter anak. Diperlukan pemodelan yang dilakukan oleh orangtua untuk mengatasi masalah ini. Upaya yang dapat dilakukan diantaranya melalui pengondisian lingkungan pengasuhan untuk mengontrol perkembangan karakter anak. Anak-anak lebih cenderung mengembangkan keterampilan bekerjasama dan berbagi, jika orangtua memperjelas bahwa orang tua mengharapkan (tapi tidak memaksa) anakanak mereka untuk melakukannya. Permintaan sopan kepada anak-anak menjadi sangat membantu dan efektif dalam penanaman dan peningkatan karakter yang baik pada anak (Eisenberg, Fabes, \& Spinrad, 2006).

Hasil penelitian menunjukkan bahwa karakteristik keluarga (pendapatan) memiliki hubungan yang positif dengan pelaksanaan fungsi keagamaan keluarga yang berimbas kepada peningkatan karakter anak. Literatur yang ada menunjukkan bahwa kondisi lingkungan keluarga, termasuk status pekerjaan orang tua, etnis, pendapatan, dan tingkat pendidikan dapat memengaruhi pencapaian perkembangan karakter anak. Siswa dari keluarga dengan status sosial ekonomi rendah cenderung menunjukkan karakter dalam interaksi sosial yang kurang baik (Vekiri, 2010). Secara khusus, anak perempuan dengan satu atau kedua orang tua dari kelompok minoritas, buruh atau pengangguran menunjukkan perkembangan sikap yang kurang baik (Tien \& Fu, 2008). Data dari studi keluarga yang hidup dalam kemiskinan (Ryan et al,, 2009) menunjukkan bahwa ibu yang dukungan sosialnya sedikit memiliki anak-anak yang kurang prososial, dengan lebih banyak masalah karakter, yang disebabkan oleh tingkat stres ibu. Anak-anak yang keluarganya memiliki dukungan sosial yang tinggi menunjukkan lebih banyak empati dan karakter yang positif terhadap anak-anak lain (Spinrad \& Eisenberg, 2009; Romano, Kohen, \& Findlay, 2010).

Karakteristik anak (usia dan jenis kelamin) tidak memiliki pengaruh terhadap karakter anak. Hasil penelitian ini berbeda dengan temuan sebelumnya yang menyatakan bahwa karakter anak perempuan lebih baik dibandingkan anak laki-laki (Puspitasari, Hastuti, \& Herawati, 2016). Usia dan jenis kelamin anak diduga tidak kuat untuk menjadi prediktor karakter anak. Hal ini disebabkan oleh kondisi dari karakteristik anak yang relatif homogen dalam penelitian ini.

Menurut Vygotsky, seorang anak tidak terlepas dari aktivitas sosialnya (Santrock, 2012). Hasil uji pengaruh menunjukkan bahwa karakteristik keluarga (lama pendidikan ibu, usia ibu, status pekerjaan ibu, pendapatan keluarga), internalisasi nilai fungsi keagamaan keluarga, dan pengondisian lingkungan berpengaruh langsung positif signifikan terhadap karakter anak. Hal ini berarti semakin tinggi pendidikan ibu dan semakin matang usianya, maka pengetahuan dan pengalaman ibu akan semakin baik (Sari \& Sunarti, 2013) sehingga karakter anak juga akan semakin baik (Tsania, Sunarti, \& Krisnatuti, 2015). Hal ini juga sejalan dengan hasil penelitian Parveen (2009) yang menyatakan bahwa pendidikan, usia ibu, dan pendapatan keluarga dapat menjadi faktor yang berpengaruh dalam praktik pengondisian lingkungan pengasuhan, termasuk di dalamnya pelaksanaan fungsi keagamaan keluarganya.

Bert (2011) mengemukakan bahwa ibu yang memiliki nilai keagamaan tinggi berpengaruh positif terhadap karakter anak. Beberapa hasil penelitian juga mengungkapkan hal yang sama, bahwa orangtua yang memiliki religiusitas tinggi berhubungan dengan pengondisian lingkungan pengasuhan yang penuh kebaikan yang nantinya akan berpengaruh positif terhadap karakter anak (Reinert, 2007; Tabitha, 2014). Hasil penelitian yang dilakukan oleh Aquino, Laven, dan McFerrant (2011) menunjukkan bahwa orangtua dengan kebaikan identitas moral 
yang tinggi memiliki pandangan kemanusiaan yang lebih positif, lebih berkeinginan untuk menjadi orang yang lebih baik, dan menanamkan nilai yang baik kepada anaknya. Orangtua melalui interaksi sosial terkecil memberikan kasih sayang atau kehangatan yang menumbuhkan kebaikan di dalam diri anak (Megawangi, 2009). Sunarti (2005) menjelaskan lebih lanjut bahwa apabila orangtua membiasakan anak dengan kegiatan sosialisasi karakter, misalnya melalui penggalian kekuatan cerita dengan menanamkan nilai kebaikan yang terusmenerus dilakukan, maka akan menjadi pola kebiasaan yang akhirnya akan membentuk karakter anak tesebut.

Pengondisian lingkungan anak antara keluarga yang satu dengan keluarga yang lainnya berbeda-beda. Hasil uji pengaruh menemukan bahwa pengondisian lingkungan berpengaruh langsung positif signifikan terhadap karakter anak. Hurlock (1994) menyatakan bahwa pengondisian lingkungan yang baik dapat memberi efek peningkatan identitas moral anak yang berdampak pada karakternya dalam bergaul dengan teman sebaya. Welbourne dan Dixon (2015) menyatakan bahwa perbedaan ekonomi, sosial budaya, agama dan keadaan politik memiliki efek yang berbeda-beda terhadap cara pandang masyarakat dalam praktik pengasuhan anak yang baik. Karakter anak terbentuk dari kualitas lingkungan pengasuhan keluarga, yaitu dengan memberikan penguatan lewat stimulasi dan kontrol, serta penghargaan dan kehangatan (Dewanggi, Hastuti, \& Herawati, 2015).

Terkadang orangtua mungkin berpikir bahwa mereka seharusnya lebih halus, tapi anakanak memerlukan petunjuk atau isyarat yang jelas. Dalam sebuah penelitian di laboratorium, Brownell, Svetlova, dan Nichols (2009) menemukan bahwa anak-anak akan berbagi secara sukarela, namun untuk mendapatkan perilaku ini orangtua perlu memberikan isyarat eksplisit tentang apa yang dia sukai atau inginkan ("Saya suka biskuit!" atau " Aku butuh cracker!"). Hal ini lebih efektif dibandingkan dengan anak yang memiliki orangtua yang selalu diam dan menunggu anak tersebut memikirkan berbagi camilan atau pada sisi lain, dia mengatakan kepada anak bahwa dia harus berbagi kerupuk (dalam bentuk perintah/paksaan).

Banyak keluarga berinteraksi dengan anak mereka dengan cara yang cenderung mendorong anak-anak untuk menjadi lebih empatik, murah hati, dan membantu. Namun tanpa disadari, keluarga melemahkan perkembangan karakter anak dengan mengandalkan praktik pengasuhan yang tidak mungkin menghasilkan karakter yang diinginkan. Misalnya, banyak orang tua percaya bahwa anak-anak akan menjadi lebih berkarakter jika diberi hadiah atau penghargaan lainnya agar "bersikap baik", Padalah hasil penelitian menunjukkan sebaliknya, yaitu meskipun penghargaan semacam itu bisa menghasilkan hasil jangka pendek, namun menjadi bumerang dalam jangka panjang, anak-anak menjadi kurang dermawan saat hadiah yang diharapkan berhenti datang ketika dia memberi orang lain sesuatu (Eisenberg, Fabes, \& Spinrad, 2006; Warneken \& Tomasello, 2008).

Ketika anak berbicara kepada orangtua tentang perasaannya, sebaiknya orang tua mendengarkan dengan baik dan "melatih" anak tentang bagaimana mengekspresikan emosi, agar anak tahu bagaimana cara mengembangkan karakternya (Garner, Dunsmore, \& Southam-Gerrow, 2008). Studi lain juga mengemukakan bahwa ketika seorang ibu menjadi terlalu terlibat dalam membahas masalah anak atau masalah emosional lainnya, anak mungkin menjadi sangat fokus pada perasaan negatifnya sendiri sehingga sulit mengatur emosi tersebut agar berempati dengan orang lain (Trommsdorff, Friedlmeier, \& Mayer, 2007). Ada bukti bahwa anak-anak sering mencoba untuk menghindari percakapan tentang pengalaman sebelumnya dengan emosi negatif, terutama jika ibu tidak menggunakan pendekatan yang menerima, mendukung, berpusat pada anak selama percakapan (Waters, Virmani, \& Thompson, 2010). Olehnya itu, perlu pemahaman yang baik bagi orangtua dalam mengondisikan lingkungan anak, agar berdampak positif terhadap perkembangan karakter anak.

\section{SIMPULAN DAN SARAN}

Dari hasil penelitian yang telah dilakukan, dapat disimpulkan bahwa: (1) ibu bekerja memiliki capaian yang lebih tinggi dibandingkan ibu tidak bekerja, pada variabel internalisasi nilai kebaikan melalui fungsi keagamaan khususnya dimensi keimanan dan variabel total karakter anak; (2) hasil uji pengaruh menemukan bahwa karakteristik keluarga (lama pendidikan ibu, usia ibu, status pekerjaan ibu, pendapatan keluarga), internalisasi nilai fungsi keagamaan, dan pengondisian lingkungan berpengaruh langsung positif terhadap karakter anak. Berdasarkan hasil penelitian, saran yang dapat 
diberikan kepada beberapa pihak antara lain: (1) pemerintah diharapkan dapat melaksanakan kebijakan terkait program peningkatan ketahanan keluarga sehingga semua keluarga mampu melaksanakan tugas dan fungsinya secara optimal, khususnya dalam menginternalisasikan nilai kebaikan karakter kepada anaknya; (2) perguruan tinggi dan LSM sebaiknya memberikan penyuluhan dan arahan tentang praktik pengasuhan yang baik yang berhubungan pelaksanaan internalisasi fungsi keagamaan dan pengondisian lingkungan, utamanya bagi ibu tidak bekerja; (3) pentingnya dukungan sosial dari keluarga besar dan masyarakat, khususnya bagi ibu bekerja sehingga anak tidak kehilangan kontrol meskipun ibu sering berada di luar rumah; (4) perlu dilakukan penelitian selanjutnya terkait internalisasi nilai kebaikan karakter melalui beberapa fungsi keluarga yang lain, seperti fungsi cinta kasih, ekonomi, perlindungan, dan sosial budaya.

\section{DAFTAR PUSTAKA}

Alam, M. S., Sattar, A., \& Chaudhury, S. I. N. A. (2011). Work family conflict of women managers in Dhaka. Asian Social Science, 7(7), 108-114.

Almani, A. S.,, Abro. A., \& Mugheri, R. A. (2012). Study of the effects of working mothers on the development of children in Pakistan. International Journal of Humanities and Social Science, 42(11), 164-171.

Almasitoh, U. H. (2011). Stres kerja ditinjau dari konflik peran ganda dan dukungan sosial pada perawat. Jurnal Psikologi Islam, 8(1), 63-82.

Aquino, K., Laven, M., \& McFerrant, B. (2011). Moral Identity and the experience of moral elevation in response to acts of uncommon goodness. Journal of Personality and Social Psychology, 100(4), 703-718. doi:10.1037/a0022540.

Bert, S. (2011). The influence of religiosity and spirituality on adolescent mothers and their teenage children. $J$ Youth Adolescence, 40(1), 72-84.

[BKKBN] Badan Kependudukan dan Keluarga Berencana Nasional. (1996). Badan kebijakan program keluarga berencana nasional. Jakarta, ID: BKKBN.

[BPS] Badan Pusat Statistik Kabupaten Bogor. (2015). Kabupaten Bogor dalam angka 2015. Bogor, ID: BPS.
Brownell, C. A., Svetlova, M., \& Nichols, S. (2009). To share or not to share: when do toddlers respond to another's needs? Infancy, 14(1), 117-130.

Dechant, A., \& Schulz, F. (2014). Scenarios for the equal division of paid and unpaid work in the transition to parenthood in Germany. Comparative Population Studies-Zeitschrift

für

Bevölkerungswissenschaft, 39, 615-644. doi:10.4232/10.CPoS-2013-06en.

Dewanggi, M., Hastuti, D., \& Herawati, T. (2015). Pengaruh kelekatan, kualitas pengasuhan, dan kualitas lingkungan pengasuhan terhadap karakter pada anak pedesaan dan perkotaan di Bogor. Jurnal IImu Keluarga dan Konsumen, $8(1)$, 20-37. doi:10.24156/jikk.2015.8.1.20.

Eisenberg, N., Fabes, R. A., \& Spinrad, T. L. (2006). Handbook of child psychology. New York, US: Routledge/Taylor \& Francis Group.

Eliana, N., \& Ratina, N. (2007). Faktor-faktor yang memengaruhi curahan waktu kerja wanita. Jurnal EPP, 4(2),11-18.

Elmanora, Muflikhati, I., \& Alfiasari. (2012). Kesejahteraan keluarga petani kayu manis. Jurnal IImu Keluarga dan Konsumen, 5(1), 128-137. doi:10.24156/jikk.2012.5.1.58.

Felton, J., Brooks, J., \& Robert, S. (1994). Family environment scale. Michigan, US: Chicago Press.

Garner, P. W., Dunsmore, J. C., \& SouthamGerrow, M. (2008). Mother-child conversations about emotions: linkages to child aggression and prosocial behaviour. Social Development, 17, 259277.

Glocks, Y., \& Stark, R. (1968., A taxonomy of religious experience. Journal for the Scientific Study of Religion, 5(3), 97-116.

Hakim, F. A., Sunarti, E., \& Herawati, T. (2014). Manajemen keuangan dan kepuasan keuangan istri pada keluarga dengan suami istri bekerja. Jurnal IImu Keluarga dan Konsumen, 7(3), 174-182. doi:10.24156/jikk.2014.7.3.174.

Herawati, T. (2012). Manajemen sumber daya keluarga dan ketahanan keluarga peserta program pemberdayaan masyarakat dan perdesaan (kasus di Kabupaten Bogor) (Disertasi). Institut Pertanian Bogor, Bogor, Indonesia. 
Hurlock. (1994). Psikologi perkembangan (Terj.). Jakarta, ID: Erlangga.

Madden, E. E., Aguiniga, D. M., \& Zellmann, K. T. (2014). Religious faith and depression among child welfare involved mothers with young children. Journal of Family Strengths, 14(7),1-20.

Megawangi, (2009), Pendidikan karakter. Depok, ID: Indonesia Heritage Foundation.

Meliani, F., Sunarti, E., \& Krisnatuti, D. (2014). Faktor demografi, konflik kerja-keluarga, dan kepuasan perkawinan istri bekerja. Jurnal IImu Keluarga dan Konsumen, $7(2)$, 133-142. doi:10.24156/jikk.2014.7.3.133.

Parveen, N. (2009). Investigating occupational stress among married and unmarried working women in Hyderabad City. Bahria Journal of Professional Psychology, 5, 21-37.

Peterson, C., \& Seligmen, M. E. (2004). Character strengths and virtues: a handbook and classification, New York, US: Oxford Univ Press.

Puspitasari, R., Hastuti, D., \& Herawati, T. (2016). Pengaruh kecerdasan spiritual ibu terhadap karakter anak usia sekolah dasar di perdesaan. Jurnal IImu Keluarga dan Konsumen, 9(2), 101-112. doi:10.24156/jikk.2013.6.3.143.

Raharjo, T. I., Puspitawati, H., \& Krisnatuti, D. (2015). Tekanan ekonomi, manajemen keuangan, dan kesejahteraan keluarga muda. Jurnal IImu Keluarga dan Konsumen, 8(1), 38-48, doi:10.24156/jikk.2015.8.1.38.

Rahmawati, S., Hastuti, D., \& Herawati, T. (2014). Analisis akses media sosial; hubungannya dengan pekembangan karakter siswa sekolah menengah kejuruan di Bogor. Jurnal IImu Keluarga dan Konsumen, 7(2), 67-74, doi:10.24156/jikk.2014.7.2.67.

Rahmiati, T. S. A., \& Puspitawati, H. (2013). Hubungan antara investasi dan kualitas anak usia sekolah pada keluarga petani. Jurnal IImu Keluarga dan Konsumen, 6(2), 154-162, doi:10.24156/jikk.2013.6.3.154.

Reinert, D. F. (2007). Self-representations, and attachment to parents: a longitudinal study of Roman Catholic College seminarians. Journal Spirituality
Counseling and Values, 49(3), 226-238. doi:10.1002/j.2161-07X.2007.tb01025.x.

Rizkillah, R., Sunarti, E., \& Herawati, T. (2015). Kualitas perkawinan dan lingkungan pengasuhan pada keluarga dengan suami istri bekerja. Jurnal IImu Keluarga dan Konsumen, 8(1), 10-19. doi:10.24156/jikk.2015.8.1.10

Romano, E., Kohen, D. E., \& Findlay, L. C. (2010). Associations among child care, family, and behavior outcomes in a nation-wide sample of preschool-aged children. International Journal of Behavioral Development, 34(5), 427440.

Runcan, P. L., \& Goian, C. (2014). Parenting practices and the development of trait emotional intelligence: a study on romanian senior high schoolers. Journal Revista de Asistent Social, 13(1), 67-78.

Ryan, R. M., Kalil, A., \& Leininger, L. (2009). Low-income mothers' private safety nets and children's socioemotional well-being. Journal of Marriage and Family, 71(2), 278-297.

Santrock, J. W. (2012). Life span development (terj. perkembangan masa hidup). Jakarta, ID: Erlangga.

Sari, F., \& Sunarti, E. (2013). Kesiapan menikah pada dewasa muda dan pengaruhnya terhadap usia menikah. Jurnal IImu Keluarga dan Konsumen, $6(3)$, 143-153. doi:10.24156/jikk.2013.6.3.143.

Slovin, M. J. (1960), Sampling. New York, US: Simon and Schuster, Inc.

Spinrad, T. L., \& Eisenberg, N. (2009). Handbook of positive psychology in schools. New York, US: Routledge/Taylor \& Francis Group.

Sunarti, E. (2005), Menggali kekuatan cerita. Jakarta, ID: PT. Elex Media Komputindo.

(2013), Tipologi keluarga di wilayah perdesaan dan perkotaan. Jurnal IImu Keluarga dan Konsumen, 6(2), 73-81. doi:10.24156/jikk.2013.6.2.73.

(2014). Empowering the care of family members to improve child nutritional status. In IFHE Activities: Family Socioeconomic and Cultural Issues, International Federation for Home Economic, 90-98. https://www.ifhe.org/1159/. 
(2015). Ketahanan keluarga Indonesia. Bogor, ID: IPB Press.

Sunarti, E., \& Fitriani. (2010). Kajian modal sosial, dukungan sosial dan ketahanan keluarga nelayan di daerah rawan bencana. Jurnal IImu Keluarga dan Konsumen, 3(2), 93-100. doi:10.24156/jikk.2010.3.2.93.

Sunarti, E., Kholifah, I., Vidiastuti, F., Kharisma, N., Rochimah, N., \& Herawati, T. (2013, July). Family vulnerability, family resource management, and family strength of aging family members. Paper presented at $5^{\text {th }}$ International Community, Work and Family Conference, University of Sydney, Sidney.

Tabitha, N. (2014). A study of the link between self-esteem and spiritual experience of parents living in the "city of sadness" of Hong Kong. Journal of the North American Association of Christians in Social Work \& Christianity, 41(1), 45-59.

Tien, F. F., \& Fu, T. T. (2008). The correlates of the digital divide and their impact on college student learning. Computers and Education, 50, 421436.

Trommsdorff, G., Friedlmeier, W., Mayer, B. (2007). Sympathy, distress, and prosocial behavior of preschool children in four cultures. International Journal of Behavioral Development, 31(3), 284-293.

Tsania, N., Sunarti, E., \& Krisnatuti, D. (2015). Karakteristik keluarga, kesiapan menikah dan perkembangan anak usia 3-5 tahun. Jurnal IImu Keluarga dan Konsumen, 8 (1), 28-37. doi:10.24156/jikk.2015.8.1.28.

Vekiri, I. (2010). Socioeconomic differences in elementary students' ICT beliefs and outof-school experience. Computers and Education, 54, 941-950.

Wardhani, R. H., Sunarti, E., \& Muflikhati, I. (2017). Ancaman, faktor protektif, aktivitas, dan resiliensi remaja: analisis berdasarkan tipologi sosiodemografi. Jurnal IImu Keluarga dan Konsumen, 10(1), $\quad$ 47-58. doi:10.24156/jikk.2017.10.1.47.

Warneken, F., \& Tomasello, M. (2008). Extrinsic rewards undermine altruistic tendencies in 20 month olds. Developmental Psychology, 44(6), 17851788.
Waters, S., Virmani, E., Thompson, R. A., Meyer, S., Raikes, A., \& Jochem, R. (2010). Emotion regulation and attachment: unpacking two constructs and their association. Journal of Psychopathology and Behavior Assessment, 32, 37-47.

Welbourne, P., \& Dixon J. (2015). Child protection and welfare. European Journal of Social Work, 19(6), 827-840.

Yimer, M., Abera, B., Mulu W., \& Bezabih, B. (2013). Knowledge, attitude and practices of high risk population on louse-borne relapsing fever in Bahir Dar City, North-West Ethiopia. Science Journal of Public Health, 2(1), 15-22. doi:10.11648/j.sjph.20130201.13. 